\title{
Investigation into sport motivations of university student, academic and administrative personal and their expectations
}

\author{
Çetin Özdilek ${ }^{1}$, Betül Altınok ${ }^{1}$, Nurullah Emir Ekinci ${ }^{1}$, Esra Aldanmaz Samuk ${ }^{2}$ and Kubilay \\ Çimen ${ }^{3 \mathrm{a}}$ \\ ${ }^{1}$ Dumlupınar University, Physical Education and Sport College, Kütahya \\ ${ }^{2}$ Osmangazi University, Eskişehir \\ ${ }^{3}$ Gelişim University, Physical Education and Sport College, Istanbul
}

\begin{abstract}
The present study aims to determine rationales and motives of students, academic and administrative personnel from the Eskisehir Osmangazi University regarding participating in sport activities and their relevant expectations from them. Totally 198 individuals were responded to the study voluntarily while number of students, academic and administrative personnel were 94, 46 and 58, respectively. "Sport Participation Motivation Scale" and "Participation Motivation Scale" consisted of 30 items concerning individuals' motives for their adherence to sport; and 8 sub-dimensions were employed as data collection tool. t-test and Variance Analysis (One-way Anova) were utilized for paired comparisons and multiple comparisons for sport participation motivation, respectively $(\mathrm{P}<0.05)$. In assessment of demographical data, frequency and percentage were utilized. It was observed that the most significant sport motive addressed by respondents was "For my physical health" $(\mathrm{N}=47$; $23.7 \%)$. Then, this was followed by the motive of "For my fitness" ( $\mathrm{N}=31$; $15.7 \%$ ). It was determined that sport motivations of participants differs according to gender, age and position $(\mathrm{P}<0.05)$. Since exercise and sport participation are considered as a significant factor reducing risks related with various physical, psychological and social problem, significant motives associated with sport participation are required to be determined and the sport programs are required to be organized.
\end{abstract}

Keywords: Sport, motivation, sport participation motivation

\footnotetext{
${ }^{\mathrm{a}}$ Corresponding author: kcimen@gelisim.edu.tr
} 


\section{Introduction}

The idea of training the body, which is one of the components constituting the entirety of the human being together with the components of mind and soul, for specific purposes is as old as the existence of humankind on the earth [1]. If human beings move, they lead their lives more dynamically and by feeling more honourable. Joy of movement is always the joy of life for children, for adults [2]. Sport is an activity which protects mental and physical health of human being and makes society more efficient and happier. It is an educational activity which plays a crucial role in the mental, social and physical development of the individual. Sport is a phenomenon which stimulates undiscovered characteristics and creative aspects of the individual and strengthens his/her will on one hand and makes contributions depending on social and economic development on the other hand [3]. Factors which direct an individual to do a sport include skills and personality features of the individual, such important figures as siblings, peers, parents, teachers and academicians and the desire to succeed [4]. None of the leisure activities where personal preferences come to the fore has all of game, pleasure, entertainment and competition elements together as in sports. Sport also helps the young develop such characteristics as respecting one another, being thoughtful to one another, obeying the rules, cooperating, acting independently, and disciplining oneself, being combatant, determined and decisive. Besides, in particular, active sport assumes significant roles in the development of contemporary human identity. It facilitates socialisation process and helps the individual develop a personality that is useful to himself and society and has strong national sentiments $[5,6,7,8,9,10,11]$.

Studies indicate that sport activities have a significant place in spending leisure times $[12,13,14]$. As a matter of fact, a report prepared by the European Council recommends that all people and especially university students should spare $70 \%$ of their leisure times to sports [15].

Kilpatrick, Hebert and Bartholomew 2005 examined the motivational differences between sport and exercise and gender differences in physical activities in their studies. At the end of the study, it was found that the main reason of doing sports are to have fun and to struggle while the main reason to do exercise is the appearance [16].

Gill et al. 1983 defined studies which aim to measure the attitudes of the individual towards physical activity rather than their reasons to do sports and stated that there are no research model and standard measurement tools with respect to this issue. Based on this, Gill et al. (1983) developed Participation Motivation Questionnaire in order to determine the reasons of young people to participate in sportive activities. In this inventory developed by Gill et al. (1983) with 1138 students attending summer sports schools, the reasons of the individuals to participate in sports are assessed in eight general dimensions as developing skills, team membership/spirit, entertainment, friendship, success/status, spending energy, physical fitness and other reasons. In this context, the aim of this study was to reveal the reasons of the individuals in the relevant groups to do sports [17]. The aim of the present study is to examine the reasons and expectations of the Academic and Administrative Staff of Eskisehir Osmangazi University with respect to doing sports.

\section{Method}

\subsection{Universe and Sampling}

Universe of the research was consisted of personnel and students at the Eskisehir Osmangazi University. Sampling of the universe was composed of volunteer students, academic and administrative personnel of the Eskisehir Osmangazi University. 


\subsection{Data Collection Tool}

In the present study, "Sport Participation Motivation Scale" was utilized as data collection tool. Sport Participation Motivation Questionnaire (PMQ) was the questionnaire used to explain motivations of individuals to participate in sport activities, which was consisted of 30 items. The original scale developed by Gill, Gross and Huddleston [17] was structured to determine the significance of respondents effective on participation of respondents into sport and exercise activities under 3-point Likert model with options of "Very Important", "Moderately Important" and "Not Important at All". Since items in the questionnaire were evaluated in the range of 1 (Very Important) to 3 (Not Important), as the total score decreases, significance of the relevant item increases. The scale utilized by Gill et al. [17] was consisted of 8 sub-dimensions (Skill Development, Team Membership/Spirit, Entertainment, Friendship, Success/Status, Spending Energy, Physical Adequacy and Other Reasons). Gill et al. [17] estimated the Cronbach's alpha coefficient for sub-dimensions in the range of .78 (Success/Status) and .30 (Friendship). The reliability of the PMQ was determined as .68 through test- re-test method.

The questionnaire was translated into Turkish by Çelebi [19] and the general reliability coefficient was estimated at .91. Oyar, Aşçı, Çelebi and [18,19] conducted reliability and validity analysis for the summer school; and 8 sub-dimensions were determined. The Cronbach's alpha internal consistency coefficient was determined for Subdimensions in the range of .61 (Skill Development) and .78 (Success/Status). Total internal consistency coefficient for the general questionnaire was estimated as .86. The Turkish questionnaire form prepared by Çelebi and employed by Oyar et al. $[18,19]$ was utilized in the present study.

\subsection{Data Analysis}

In the analysis collected data within the scope of the study, IBM SPSS 21 statistical package software was harnessed. At first, descriptive statistics of variables were investigated; obtained findings were explained by frequency and percentages. In the sport participation motivation questionnaire, whereas t-test was used for comparisons of dual sets; Variance Analysis (one-way anova) was utilized in comparison of multiple sets $(\mathrm{P}<.05)$.

\section{Findings}

Totally 198 volunteer personnel and students were participated into the study. It was determined that number of female and male respondents were $87(43.9 \%)$ and $111(56.1 \%)$, respectively. In terms of distribution of respondents, numbers of academicians, administrative personnel and students were 46 (23.2\%), $58(29.3 \%)$ and $94(47.5 \%)$, respectively. Moreover, in terms of their age distribution, $73(36.9 \%)$ were in the group of $18-22 ; 46(23.2 \%)$ were in the group of $23-27 ; 26(13.1 \%)$ were in the group of $28-32 ; 18$ $(9.1 \%)$ were in the group of $33-37$; and $35(17.7 \%)$ were in the group of $38 \leq$. The most significant sport motive addressed by respondents was determined as "For my physical health" $(\mathrm{N}=47 ; 23.7 \%)$. The second most significant sport motive was determined as "For my fitness" ( $\mathrm{N}=31 ; 15.7 \%)$. When it was considered at sub-dimension level, it was observed that average scores obtained with respect to the sub-dimensions in the PMQ exhibit difference according to the factors. Findings as a result of the analysis conducted along the purposes of the study were exhibited in tables below. 
Table 1. t-Test Results of Analysis of Average Sport Participation Motivation SubDimension Scores of Subjects

\begin{tabular}{lcccccc}
\hline Sub-Dimensions & Gender & $\mathbf{N}$ & $(\mathbf{X})$ & sd & t & p \\
\hline \multirow{2}{*}{ Succes/Status } & Female & 87 & 1,68 & 0,53 & 2,023 & 0,044 \\
& Male & 111 & 1,54 & 0,46 & & \\
\hline \multirow{2}{*}{ Team Membership/Sprit } & Female & 87 & 1,63 & 0,55 & 1,715 & 0,088 \\
& Male & 111 & 1,51 & 0,45 & & \\
\hline \multirow{2}{*}{ Fun } & Female & 87 & 1,51 & 0,45 & 1,369 & 0,172 \\
& Male & 111 & 1,43 & 0,43 & & \\
\hline \multirow{2}{*}{ Friend } & Female & 87 & 1,92 & 0,61 & 2,067 & 0,040 \\
& Male & 111 & 1,75 & 0,54 & & \\
\hline \multirow{2}{*}{ Competing } & Female & 87 & 1,88 & 0,61 & 4,744 & 0,000 \\
& Male & 111 & 1,50 & 0,51 & & \\
\multirow{2}{*}{ Skills Development } & Female & 87 & 1,43 & 0,46 & 1,395 & 0,165 \\
& Male & 111 & 1,34 & 0,39 & & \\
\hline \multirow{2}{*}{ Movement/Activity } & Female & 87 & 1,23 & 0,33 & $-0,973$ & 0,332 \\
& Male & 111 & 1,27 & 0,35 & & \\
\hline Energy Consume/Physical & Female & 87 & 1,17 & 0,23 & $-1,827$ & 0,069 \\
Fitness & Male & 111 & 1,24 & 0,30 & & \\
\hline
\end{tabular}

$\mathrm{df}=196$

According to Table 1, results of t-test conducted to determine gender difference in sport participation motivation scores of participant subjects revealed that there was statistically significant difference in "Competition" $(\mathrm{t}=4,744 ; \mathrm{p}<0,05)$, "Success/Status" $(\mathrm{t}=2.023$; $\mathrm{p}<0.05)$ and "Friend" $(\mathrm{t}=2.067 ; \mathrm{p}<0.05)$ sub-dimensions. Male respondents thought that "Competition", "Success/Status" and "Friend" sub-dimensions were more important with respect to the female participants. "Team membership/spirit", "Entertainment", "Skill development", "Activity/Being Active" and "Energy Spending/Physical Adequacy" subdimensions were not found statistically significant $(\mathrm{p}>0.05)$.

According to Table 2, as a result of the one way variance analysis (ANOVA) conducted to determine the difference among sport participation motivations of subjects, "Competition" $\left(\mathrm{F}_{(197)}=3,271 ; \mathrm{P}<0.05\right)$ and "Skill development" $\left(\mathrm{F}_{(197)}=4,091 ; \mathrm{P}<0.05\right)$ subdimensions were found to be significantly different with respect to age. According to the Tukey HSD test conducted in the second stage, conducted to determine the age groups exhibiting significant difference, for the respondents from the age group of 18-22 $(1.571 \pm 0.565)$, in terms of sport participation motivation, competition sub-dimension was more important in comparison with respondents from the age group of $38 \leq(1.981 \pm 0.610)$ $(\mathrm{P}<0.05)$. Again, for the respondents from the age group of 23-27 (1.608 \pm 0.508$)$, the Competition sub-dimension was more important in comparison with the respondents from the age group of $38 \leq(1.981 \pm 0.610)(\mathrm{p}<0.05)$. Based on these results, it was concluded that Competition and struggle inside the sport were more important for younger respondents in comparison with the older respondents. 
Table 2. Variance Analysis Results of Average Sport Participation Motivation Sub-Dimension Scores of Subjects According to Age Variable

\begin{tabular}{|c|c|c|c|c|c|c|}
\hline Sub-Dimensions & Age & $\mathbf{N}$ & Mean & $\begin{array}{c}\text { Std. } \\
\text { Deviation }\end{array}$ & $\mathbf{F}$ & $\mathbf{p}$ \\
\hline \multirow{5}{*}{ Succes/Status } & $18-22$ & 73 & 1,5315 &, 42586 & \multirow{5}{*}{0,959} & \multirow{5}{*}{0,43} \\
\hline & $23-27$ & 46 & 1,6043 & ,47794 & & \\
\hline & $28-32$ & 26 & 1,5846 &, 53643 & & \\
\hline & $33-37$ & 18 & 1,6667 &, 54880 & & \\
\hline & $38+$ & 35 & 1,7200 &, 57640 & & \\
\hline \multirow{5}{*}{$\begin{array}{c}\text { Team } \\
\text { Membership/Sprit }\end{array}$} & $18-22$ & 73 & 1,5993 & ,48186 & \multirow{5}{*}{0,849} & \multirow{5}{*}{0,49} \\
\hline & $23-27$ & 46 & 1,4511 & ,51267 & & \\
\hline & $28-32$ & 26 & 1,5577 & ,42016 & & \\
\hline & $33-37$ & 18 & 1,6250 &, 62573 & & \\
\hline & $38+$ & 35 & 1,6143 &, 47875 & & \\
\hline \multirow{5}{*}{$\begin{array}{c}\text { Consume } \\
\text { Energy/Physical } \\
\text { Fitness }\end{array}$} & $18-22$ & 73 & 1,2219 & ,27399 & \multirow{5}{*}{0,674} & \multirow{5}{*}{0,61} \\
\hline & $23-27$ & 46 & 1,1826 & ,28230 & & \\
\hline & $28-32$ & 26 & 1,1923 & ,21526 & & \\
\hline & $33-37$ & 18 & 1,3000 & ,30870 & & \\
\hline & $38+$ & 35 & 1,2000 & ,27865 & & \\
\hline \multirow{5}{*}{ Friend } & $18-22$ & 73 & 1,8722 & ,59212 & \multirow{5}{*}{0,258} & \multirow{5}{*}{0,90} \\
\hline & $23-27$ & 46 & 1,8115 & ,60719 & & \\
\hline & $28-32$ & 26 & 1,7823 & ,48034 & & \\
\hline & $33-37$ & 18 & 1,7406 &, 50563 & & \\
\hline & $38+$ & 35 & 1,8383 & ,63345 & & \\
\hline \multirow{5}{*}{ Fun } & $18-22$ & 73 & 1,4623 & ,38791 & \multirow{5}{*}{1,702} & \multirow{5}{*}{0,15} \\
\hline & $23-27$ & 46 & 1,3533 & ,44590 & & \\
\hline & $28-32$ & 26 & 1,5192 & ,38680 & & \\
\hline & $33-37$ & 18 & 1,4306 & ,59905 & & \\
\hline & $38+$ & 35 & 1,6000 &, 47045 & & \\
\hline \multirow{5}{*}{ Competing } & $18-22$ & 73 & 1,5711 &, 56593 & \multirow{5}{*}{3,271} & \multirow{5}{*}{0,01} \\
\hline & $23-27$ & 46 & 1,6089 & ,50869 & & \\
\hline & $28-32$ & 26 & 1,6158 &, 54754 & & \\
\hline & $33-37$ & 18 & 1,6856 &, 74563 & & \\
\hline & $38+$ & 35 & 1,9814 &, 61056 & & \\
\hline \multirow{5}{*}{ Skills Development } & $18-22$ & 73 & 1,3282 & ,34063 & \multirow{5}{*}{4,091} & \multirow{5}{*}{0,00} \\
\hline & $23-27$ & 46 & 1,2891 & ,39532 & & \\
\hline & $28-32$ & 26 & 1,3081 & ,29838 & & \\
\hline & $33-37$ & 18 & 1,6294 & ,57027 & & \\
\hline & $38+$ & 35 & 1,5429 &, 52541 & & \\
\hline \multirow{5}{*}{ Movement/Activity } & $18-22$ & 73 & 1,2504 & ,34589 & \multirow{5}{*}{1,425} & \multirow{5}{*}{0,27} \\
\hline & $23-27$ & 46 & 1,1733 & ,28732 & & \\
\hline & $28-32$ & 26 & 1,2300 & ,30943 & & \\
\hline & $33-37$ & 18 & 1,3506 & ,40352 & & \\
\hline & $38+$ & 35 & 1,3234 & ,36636 & & \\
\hline
\end{tabular}

Table 3. Age groups with significant difference in their sport participation motivation levels

\begin{tabular}{|c|c|c|c|c|c|}
\hline $\begin{array}{l}\text { Tukey HSD } \\
\text { Dependent Variable }\end{array}$ & & & $\begin{array}{c}\text { Mean Difference } \\
\text { (I-J) }\end{array}$ & Std. Error & Sig. \\
\hline Competing & $18-22$ & $38+$ &,$- 41033^{*}$ & , 11869 & ,006 \\
\hline Competing & $23-27$ & $38+$ &,$- 37252^{*}$ & ,12949 &, 036 \\
\hline Skills Development & $18-22$ & $33-37$ &,$- 30123^{*}$ & ,10804 & 046 \\
\hline Skills Development & $23-27$ & $33-37$ &,$- 34031^{*}$ & ,11413 & 027 \\
\hline Skills Development & $23-27$ & $38+$ &,$- 25373^{*}$ & ,09208 & 050 \\
\hline
\end{tabular}


According to the differences in the Skill development sub-dimension, for the respondents from the age group of 18-22 (1.328 \pm 0.340$)$, Skill development was more important in comparison with the respondents from the age group of 33-37 (1.629 \pm 0.570$)$ in terms of sport participation motivation $(\mathrm{P}<0.05)$. Again, for the respondents in the Skill development sub-dimension, from the age group of 23-27 (1.289 \pm 0.395$)$ Skill development was more important in comparison with the respondents from the age group of 33-37 $(1.629 \pm 0.570)$ and $38 \leq(1.542 \pm 0.525)$ in terms of sport participation motivation $(\mathrm{P}<0.05)$. Based on these results, it was considered that skill development gained through sport was more important for younger respondents in comparison with the older ones (See: Table 4.) No any statistically significant difference was determined with Success/Status, Team membership/spirit, Energy Spending/Physical Adequacy, Friend, Entertainment and Activity/Being active sub-dimensions ( $\mathrm{p}>0.05)$.

Table 4. Results of Variance Analysis on Subjects' Position According to the Sport Participation Motivation Sub-dimension

\begin{tabular}{|c|c|c|c|c|c|c|}
\hline Sub-Dimensions & Position & $\mathbf{N}$ & Mean & $\begin{array}{c}\text { Std. } \\
\text { Deviation }\end{array}$ & $\mathbf{F}$ & p \\
\hline \multirow{3}{*}{ Success/Status } & Academic Staff & 46 & 1,7435 & ,54758 & \multirow{3}{*}{3,585} & \multirow{3}{*}{0,030} \\
\hline & Administrative Staff & 58 & 1,4862 & ,47108 & & \\
\hline & Student & 94 & 1,6021 & , 46420 & & \\
\hline \multirow{3}{*}{ Team Membership/Sprit } & Academic Staff & 46 & 1,5978 & ,48442 & \multirow{3}{*}{1,656} & \multirow{3}{*}{0,194} \\
\hline & Administrative Staff & 58 & 1,4655 & ,46934 & & \\
\hline & Student & 94 & 1,6090 & ,51137 & & \\
\hline \multirow{3}{*}{$\begin{array}{c}\text { Energy Consumption/Physical } \\
\text { Fitness }\end{array}$} & Academic Staff & 46 & 1,1957 & ,26496 & \multirow{3}{*}{0,298} & \multirow{3}{*}{0,742} \\
\hline & Administrative Staff & 58 & 1,2345 & ,27051 & & \\
\hline & Student & 94 & 1,2064 & ,27894 & & \\
\hline \multirow{3}{*}{ Friend } & Academic Staff & 46 & 1,9352 & ,56913 & \multirow{3}{*}{5,272} & \multirow{3}{*}{0,006} \\
\hline & Administrative Staff & 58 & 1,6264 & ,54511 & & \\
\hline & Student & 94 & 1,9006 & ,57778 & & \\
\hline \multirow{3}{*}{ Fun } & Academic Staff & 46 & 1,5380 & ,51631 & \multirow{3}{*}{1,019} & \multirow{3}{*}{0,363} \\
\hline & Administrative Staff & 58 & 1,4138 & ,40162 & & \\
\hline & Student & 94 & 1,4628 & , 42590 & & \\
\hline \multirow{3}{*}{ Competing } & Academic Staff & 46 & 1,7172 & ,64054 & \multirow{3}{*}{0,439} & \multirow{3}{*}{0,645} \\
\hline & Administrative Staff & 58 & 1,6962 &, 57716 & & \\
\hline & Student & 94 & 1,6280 & ,57669 & & \\
\hline \multirow{3}{*}{ Skills Development } & Academic Staff & 46 & 1,4713 & ,53408 & \multirow{3}{*}{1,387} & \multirow{3}{*}{0,252} \\
\hline & Administrative Staff & 58 & 1,3674 & ,42241 & & \\
\hline & Student & 94 & 1,3469 & ,35595 & & \\
\hline \multirow{3}{*}{ Movement/Activity } & Academic Staff & 46 & 1,3474 & ,40964 & \multirow{3}{*}{2,542} & \multirow{3}{*}{0,081} \\
\hline & Administrative Staff & 58 & 1,2407 & ,32922 & & \\
\hline & Student & 94 & 1,2119 & ,30052 & & \\
\hline
\end{tabular}

Table 5. Groups with Significant Differences in Their Sport Participation Motivations

\begin{tabular}{llcccc}
\hline & \multicolumn{2}{c}{$\begin{array}{c}\text { Tukey HSD } \\
\text { Dependent Variable }\end{array}$} & $\begin{array}{c}\text { Mean Difference } \\
\text { (I-J) }\end{array}$ & $\begin{array}{c}\text { Std. } \\
\text { Error }\end{array}$ & Sig. \\
\hline Success/Statu & Academic Staff & Administrative Staff & &, 09608 &, 022 \\
Friend & Academic Staff & Administrative Staff &, $30884^{*}$ &, 11183 &, 017 \\
Friend & Academic Staff & Administrative Staff &, $27426^{*}$ &, 09457 &, 012 \\
\hline
\end{tabular}

According to Table 4, as a result of one way Anova variance analysis to determine differences among positions (Academic Personnel, Administrative Personnel and Student) of subjects in terms of sport participation motivations, significant differences were 
determined in "Success/Status" $(\mathrm{F}(197)=3.585 ; \mathrm{P}<0.05)$ and "Friend" $(\mathrm{F}(197)=5,272$; $\mathrm{P}<0.05)$ sub-dimensions. As a result of the Tukey HSD test the second phase to determine the significant differences among groups, for the respondents from the Academic Personnel group (1.743 \pm 0.547$)$, Success/Status sub-dimension was less important in terms of sport participation motivation in comparison with the respondents from the Administrative Personnel group $(1.486 \pm 0.471)(\mathrm{P}<0.05)$.

With respect to the differences in Friend sub-dimension, for the respondents from the Academic Personnel group (1.935 \pm 0.569$)$, Friend sub-dimension was less important in terms of sport participation motivation in comparison with the respondents from the Administrative Personnel group $(1.626 \pm 0.545)(\mathrm{P}<0.05)$. Again, for the respondents from the Student group (1.900 \pm 0.577$)$, Friend sub-dimension was less important in terms of sport participation motivation in comparison with the respondents from the Administrative Personnel group $(1.626 \pm 0.545)(\mathrm{P}<0.05)$. Based on these findings, it was considered that Success/Status and Friend factors gained through sport were more important for the respondents from the Administrative Personnel group in comparison with the respondents from the Academic Personnel and Student groups.

\section{Discussion}

The present study aimed to determine sport participation motivation and the relevant rationales of students, academic and administrative personnel at the Eskişehir Osmangazi University. As a result of the descriptive analyses, the most significant sport motivation indicated by respondents was "For my physical health". The second most significant sport motivation was indicated "For my fitness". When it was considered at sub-dimensional level, it was determined that average scores of respondents, which were gained according to the sub-dimensions of the PMQ, displayed difference. Respondents indicated the most significant factors in terms of sport participation motivation as "Energy Spending/Physical Adequacy" and "Activity/Being Active". The least significant factors were indicated as "Friend" sub-dimension.

As a result of the conducted analyses, when sport participation motivation was investigated according to gender, male respondents consider "Competition", "Success/Status" and "Friend" sub-dimensions more important than the significance level attached by female respondents. These obtained findings conform to the relevant studies in the literature. Kazak [20] reported that average scores of male athlete respondents based on the "Competition" sub-scale were statistically significantly lower than the average scores of female athletes. This finding revealed that the Competition dimension was more important for male athletes with respect to female peers.

As a result of the analyses, when sport participation motivation was investigated according to age groups, Competition sub-dimension was found more important by the respondents from the age group of 18-22 with respect to the ones from the group of $38 \leq$. Again, for the respondents from the age group of 23-27, the Competition sub-dimension was found more important in terms of the sport participation motivation in comparison with the ones from the age group of $38 \leq$. On the basis of these findings, it was considered that competitions and challenges experienced in sport practices were considered as more important by younger respondents.

For the respondents from the age group of 18-22, Skill development was considered more important in terms of sport participation motivation in comparison with the ones from the age group of 33-37. Again, Skill development was considered more important by the respondents from the age group of 23-27 in terms of sport participation motivation in

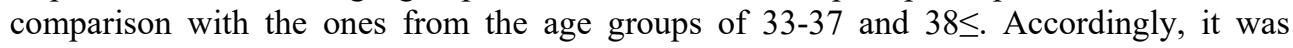


considered that skill development gained through the sport practices were found more important by younger respondents.

When sport participation motivations of respondents in the positions of Academic Personnel, Administrative Personnel and Student were investigated, Success/Status and Friend sub-dimension was less important for the respondents from the Academic Personnel group in terms of sport participation motivation in comparison with the ones from the Administrative Personnel group. Again, the Friend sub-dimension was found less important by the respondents from the Student group in terms of sport participation motivation in comparison with the ones from the Administrative Personnel group. On the basis of these results, it was concluded that the respondents from the Administrative Personnel group found Success/Status and Friend factors gained through sport activities more important in comparison with the ones from Academic Personnel and Student groups.

\section{Results}

Conclusively, the most significant sport motivation indicated by the respondents was "For physical health". The second most important sport motivation was determined as "For my fitness". The respondents indicated the most important factors as "Energy Spending/Physical Adequacy" and "Activity/Being Active" in terms of sport participation motivation. The least significant factor was determined as "Friend" sub-dimension. When sport participation motivation was investigated according to gender, male respondents found "Competition", "Success/Status" and "Friend" sub-dimensions more important than the female respondents.

As a result of analyses, when sport participation motivation was investigated according to age groups, it was determined that competition and challenge in sport practices and skill development gained through sport were more important for young respondents in comparison with older respondents. When sport participation motivations of respondents in the positions of Academic Personnel, Administrative Personnel and Student were investigated it was observed that Success/Status and Friend factors gained through sport activities were considered more important by the respondents from the Administrative Personnel group in comparison with the respondents from the Academic Personnel and Student groups. Since exercise and sport participation are significant factors reducing risk associated with numbers of physical, psychological and social problem, the most effective factors on sport participation are required to be determined so that exercises and sport programs are organized according to these factors.

\section{References}

1. Alpman, C., Physical Training Within The Integrity Of Education And Its Progress Through The Ages. Ministry Of National Education Publishing House, 1st Edition. İstanbul (1972).

2. Grössing, S., Body-Sports-Movement "Basic Concepts Of Sports Pedagogy, Change Of Meaning Of Physical Training" 1st Symposium On Physical Training And Sports In Education Institutions. Ministry Of National Education, Department Of Physical Training, Sports And Scouting In Schools, (Translated By: Adnan Orhon, Metin Sayın), Ministry Of National Education Publishing House, İzmir, (1991).

3. Erkal, M., Sports In Terms Of Sociology. Ministry Of National Education Publishing House, P, 57. Ankara, (1986). 
4. Kılcıgil, E., Relations of Social Environment and Sport, Bağırgan Publishing House, 158-161, Ankara, (1998).

5. Kane, J.E. "Personality And Physical Ability" International Congress Of Sports Science. Tokyo, 1964.

6. Gsb. Speeches Of The Scientific Meeting On Youth And Society: Ministry Of Youth And Sports, 1982.

7. Dpt. Physical Training and Sport. Ankara: Prime Ministry Publications, 1984. 5th Five Year Development Plan Special Commission Report, Sport, Ankara. State Planning Organisation Publications, (1983).

8. Demirbolat, A. Society and Sport. Ankara: Kadıŏlu Printing House, (1988).

9. Koç, Ş. "General Overview to Physical Training Activities In Secondary Education: New Approaches And Practices-Aims-Methods-Techniques" Physical Training And Problems In Secondary Education Institutions, Ankara, Ted Publications, 3-22. (1988).

10. Orhun, A, "New Didactic Approaches in Physical Training And Sport In Schools" 1st National Sports Sciences Symposium, Papers. Ankara H.U Publications, (1990).

11. Saluman, K. "Sport In Terms Of Philosophy and Sociology". Translated By: Orhun, A. Sports Sciences Bulletin. 1,3-4:5-9, December (1990).

12. Mutlutürk, N. "Sports and Problems in Higher Education" Unpublished Master's Thesis. İzmir, (1982).

13. Eryaşar, D. "Spending Leisure Times and Sport" Unpublished Master's Thesis, İzmir: (1985).

14. Ünal, Semra. "Place And Duties Of The Family In Spending Leisure Times" Life And Education. 1,16:9-12, May-June, (1991).

15. Kilpatrick M, Hebert E, Bartholomew J. "College Students' Motivation For Physical Activity: Differentiating Men's And Women's Motives For Sport Participation and Exercise" Http://Epc.Edb.Utexas.Edu/Education/Assets/Files/Khe/Bartholomew\%20publicatoins/ College $\% 20$ student's\%20motivatin\%20for\%20physical\%20activity.Pdf reached date 17/03/2016.

16. Gill D., Gross J., \& Huddleston S. Participation Motivation In Youth Sports. Int J Sport Psychology (1983)

17. Oyar Z., Aşçı F., Çelebi M., \& Mülazımoğlu Ö. Reliability And Validity Study For Sport Participation Motivation, Sport Science Magazine, (2001).

18. Çelebi A. (Leader Stereotypes Of In Middle East Technical University Physical Activity Clubs) Unpublished Master Thesis, Metu, Ankara (1993).

19. Kazak Ö.O., Evaluation Of Sport Participation Motives of Children Aged 9-14: A Case Study of Kütahya City. Unpublished Master Thesis, Dumlupınar University, Institute Of Social Sciences, Department of Physical Education And Sports Science, Kütahya, (2007). 